\title{
Synthesis, Characterization and Glass - Reinforced Composites of Thiourea - Formaldehyde - Phenol Resin
}

\author{
KANUPRASAD DAHYALAL PATEL*, DHIRUBHAI J. DESAI, MANISH M. MOREKAR, \\ and YOGESH SHRIKANT TILAK \\ Chemistry Department, V.P. \& R.P.T.P. Science College, \\ Sardar Patel University, Vallabh Vidyanagar - 388 120, Gujarat, India
}

Received 13 August 2004; Accepted 10 Sep 2004

\begin{abstract}
N}, \mathrm{N}$-'Dimethylol thiourea-formaldehyde (DMTUF) resin having the methylol group $\left(\mathrm{CH}_{2} \mathrm{OH}\right)$ has been prepared and characterized. The condensation of DMTUF resin with Phenol $(P)$ was carried out in the presence of alcoholic alkali catalyst at varying ratios of DMTUF: $P$, namely 1:1, 1:1.5 and 1:2. The resultant DMTUFP resin was characterized by elemental analysis, IR spectral studies, number average molecular weight $\left(\mathbf{M}_{\mathbf{n}}\right)$ estimated by non-aqueous conductometric titration, and thermo gravimetry. The curing study of DMTUFP resin with hexamethylene tetramine (HMTA) was monitored by differential scanning calorimetry (DSC) and kinetic parameters were evaluated. Glass-reinforced composites based on the DMTUFP-HMTA system have also been prepared and characterized.
\end{abstract}

Key words N,N'-Dimethylol thiourea-formaldehyde, dimethylol thiourea-formaldehyde phenol, number average molecular weight, glass reinforced composites..

\section{Introduction}

The study of $\mathrm{N}, \mathrm{N}^{\prime}$-Dimethylol thiourea-formaldehyde (DMTUF) resinification is well established. ${ }^{1-7}$ The DMTUF resin, having two $\mathrm{CH}_{2} \mathrm{OH}$ groups, have found many applications, for example in corrosion protection of building materials and metallic surfaces, polymerisation accelerators, decolourating hair, flame resistant agent, coating, gelling agent, cross-linking agents, adhesives, binders, finishing agents, insect proofing in textiles. ${ }^{8-20}$ Like resol (having $\mathrm{CH}_{2} \mathrm{OH}$ self-curable groups) such resin (i.e. having $\mathrm{CH}_{2} \mathrm{OH}$ groups) may afford condensation with phenolic derivatives. Hence it was thought interesting to explore the field of DMTUFP condensation.

The present communication comprises the synthesis, characterization of DMTUF resin and its postreaction with phenol. The resulting resin was studied for their curing characteristic with hexamethylenetetramine (HMTA) on DSC. Glass reinforcement of DMTUFP-HMTA has also been studied. The whole process is show $n$ in scheme 1.

\section{Experiment}

All the chemicals used were of laboratory grade.

Synthesis of Dimethylol thiourea-formaldehyde (DMTUF) resin

These were prepared by slight modification of the method reported. ${ }^{1}$. A mixture of Thiourea (1 mole), formaldehyde ( 2 mole) and $2.5 \%$ alcoholic $\mathrm{KOH}$ was heated at $50^{\circ} \mathrm{C}$ with constant stirring for $75 \mathrm{~min}$. 
The resulting mixture was cooled at room temperature. The so-called resin obtained was in the form of colourless thick liquid. It was neutralized by acetic acid and dried azeotropically. The yield was $90 \%$. Analysis of DMTUF resin is given in Table 1 and Table 2 .

\section{Synthesis of DMTUF- Phenol (DMTUFP) resin}

The DMTUF resin and phenol in a molar ratio of 1:1, 1:1.5 and 1:2 were refluxed in the aqueous solution of $2.5 \% \mathrm{KOH}$ of the total weight for two hours. The resin prepared, was with a slight modification reported [21]. The supernatant aqueous layer was decanted and the resultant resin was washed with large amount of distilled water to remove unreacted material. The water was removed by vacuum. All three resin obtained were thick yellowish liquids. The yields were 85 to $90 \%$. Details of all three resin are given Tables 1 and 2 .

Composite fabrication

A typical method of fabrication for composites is given below.

A suspension of freshly prepared DMTUFP resin (2) and HMTA in acetone was prepared and was stirred well for 3 minutes.The suspension mixture was applied with a brush to a $250 \mathrm{~mm} \times 250 \mathrm{~mm}$ fibre-glass cloth and the solvent was allowed to evaporate. The 10 dried prepegs prepared in this way were stacked one on top of another and pressed between steel plates coated with a Teflon film release sheet and compressed in a flat platen press under about 70 psi pressure. The prepeg stacks were cured by heating at $100^{\circ} \mathrm{C}$ for 4 hours and post-cured at $135 \pm 5^{\circ} \mathrm{C}$ for 8 hours in air circulation oven. The composite so obtained was cooled to $50^{\circ} \mathrm{C}$ before the pressure was released. Test specimens were made by cutting the composites and machining them to final dimensions. The $\mathrm{C}$ and $\mathrm{H}$ contents were estimated by means of a Carlo Erba (Italy) elemental analyser. The IR spectra were taken in KBr pellets using Nicolet-400 DR FTIR spectrophotometer.

Non-aqueous condutometric titration of DMTUF and DMTUFP resin was carried out in pyridine against standard sodium methanolate in pyridine as titrant. The $\bar{M}_{n}$ value of each sample was calculated according to the method reported. $22,23,24$.

Curing of the DMTUFP-HMTA system was carried out by differential scanning calorimetry. A Du Point 900 DSC was for this study. The instrument was calibrated using standard materials with known heats of fusion. Curing was carried out using a single heating rate $\left(10 \mathrm{~K} \mathrm{~min}^{-1}\right)$. The sample weight for this investigation was in the 4 to $5 \mathrm{mg}$ range; an empty cell was used as a reference. Cured samples were subjected to thermogravimetric analysis (Universal V2.6D TA instruments ) in air at a heating rate of $10^{\circ} \mathrm{Cmin}^{-1}$.

All the chemical, mechanical and electrical tests of the prepared composites were conducted according to ASTM methods following the method reported. ${ }^{25}$

DMTUF condensation was performed by slight modification of previous reported method. ${ }^{1}$ The resultant DMTUF resin is a transparent viscous liquid. All the properties are given in table 1 and table 2. The resin having active $-\mathrm{CH}_{2} \mathrm{OH}$ group is used for condensation with phenol, bearing in mind that (commercially base catalysed A-stage P-F condensate) resols are functioning in situ post-curing. DMTUF condensates were obtained in the form of yellowish semisolids to thick liquids. They (freshly prepared) are soluble in most polar organic solvents. On longer storage they harden. Efflux viscometry study of only the liquid resin of DMTUFP has been attempted and the data are included in table 2. It was observed that in the absence of phenol, DMTUFP remains relatively intact under similar conditions. However, it will be cross-linked only at elevated temperature $\left(135-160^{\circ} \mathrm{C}\right)$. Elemental analysis of all the resin is consistent with the structure predicted (scheme 1).. The IR spectra of all three resin comprise important bands due to the DMTUFP moiety and aromatic moiety. The broad bands appeared from 3360 to $3800 \mathrm{~cm}^{-1}$ with inflections at 3355 and $2650 \mathrm{~cm}^{-1}$. This is due to the polymeric groups. The first two inflections may arise from the asymmetric and symmetric vibration of $-\mathrm{NH}$ and $-\mathrm{HN}-\mathrm{CS}-\mathrm{NH}-$ systems. The bands at 755 and $823 \mathrm{~cm}^{-1}$ may be attributed to adjacent $\mathrm{H}$ - atoms or $1,2-$ or $1,4-$ substituted aromatic rings. The band at $1105 \mathrm{~cm}^{-1}$ may be attributed to the group. Hence on the basis of these observations and the reactive site present in the monomer concerned (i.e. DMTUF and phenols) the most probable structure of such an DMTUFP resin may be shown in scheme 1. 

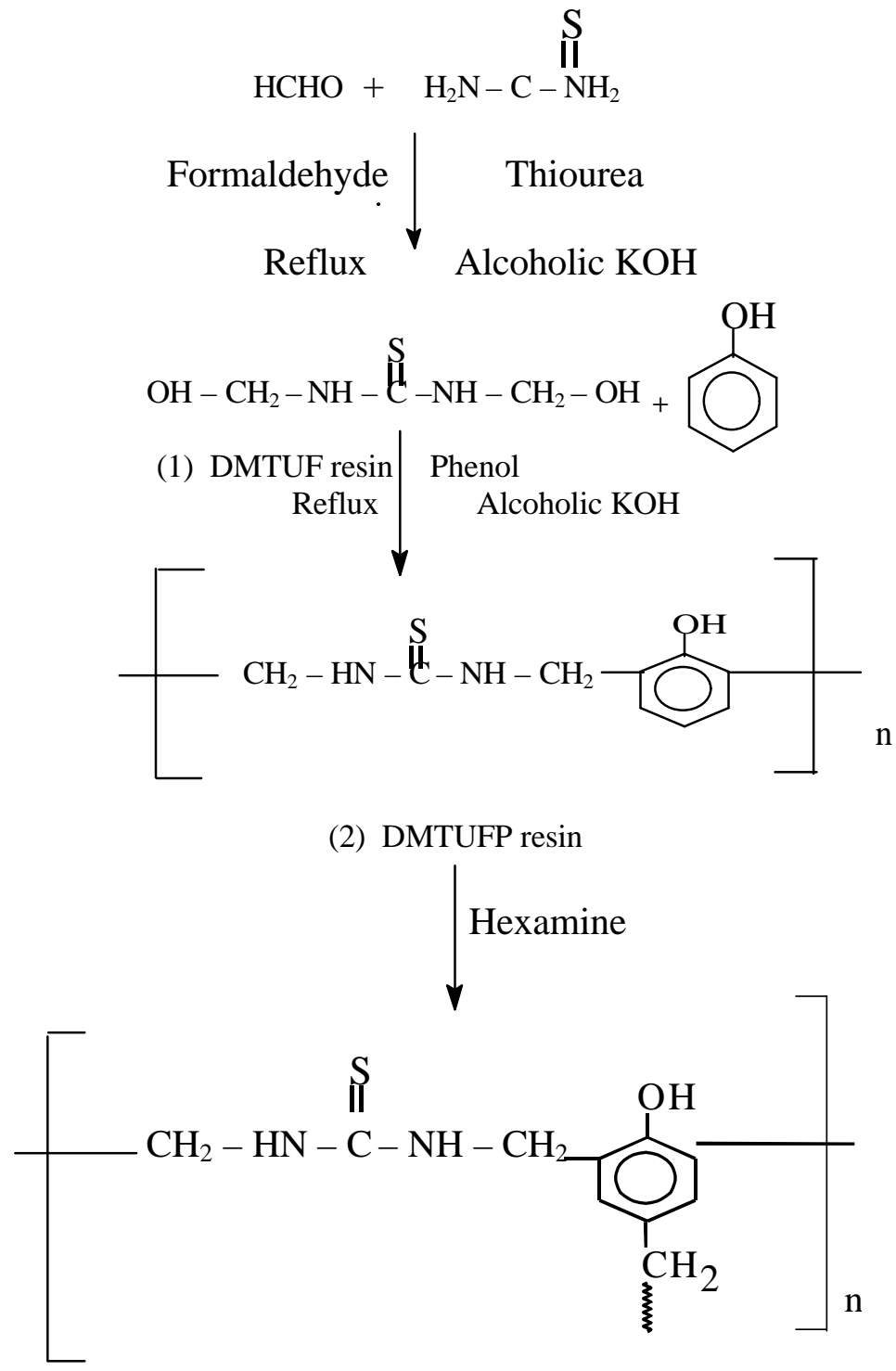

Cured Product

Scheme 1. Thiourea-formaldehyde-phenol resin

DMTUF condensation was performed by slight modification of previous reported method. ${ }^{1}$ The resultant DMTUF resin is a transparent viscous liquid. All the properties are given in Table 1 and Table 2. The resin having active $-\mathrm{CH}_{2} \mathrm{OH}$ group is used for condensation with phenol, bearing in mind that (commercially base catalysed A-stage P-F condensate) resols are functioning in situ post-curing. DMTUF condensates were obtained in the form of yellowish semisolids to thick liquids. They (freshly prepared) are soluble in most polar organic solvents. On longer storage they harden. Efflux viscometry study of only the liquid resin of DMTUFP has been attempted and the data are included in table 2. It was observed that in the absence of phenol, DMTUFP remains relatively intact under similar conditions. 
However, it will be cross-linked only at elevated temperature $\left(135-160^{\circ} \mathrm{C}\right)$. Elemental analysis of all the resin is consistent with the structure predicted (scheme 1). The IR spectra of all three resin comprise important bands due to the DMTUFP moiety and aromatic moiety. The broad bands appeared from 3360 to $3800 \mathrm{~cm}^{-1}$ with inflections at 3355 and $2650 \mathrm{~cm}^{-1}$. This is due to the polymeric groups. The first two inflections may arise from the asymmetric and symmetric vibration of $-\mathrm{NH}$ and $-\mathrm{HN}-\mathrm{C}-\mathrm{NH}-$ systems. The bands at 755 and $823 \mathrm{~cm}^{-1}$ may be attributed to adjacent $\mathrm{H}$ - atoms or 1,2 - or 1,4 substituted aromatic rings. The band at $1105 \mathrm{~cm}^{-1}$ may be attributed to the group. Hence on the basis of these observations and the reactive site present in the monomer concerned (i.e. DMTUF and phenols) the most probable structure of such an DMTUFP resin may be shown in scheme 1.

The $\bar{M}_{n}$ values of all three resin estimated by non - aqueous conductometric titration are shown in the Table 2. The values indicate that decreases with increase in molar proportion of phenol.

As the DMTUFP resin produced can react with curing agent like HMTA the cure reaction of DMTUFPHMTA was studied for DMTUF: P : HMTA ratios of $1: 1: 1,1: 1.5: 1$ and $1: 2: 1$. The data obtained from DSC scans are given in table 3 . From the DSC thermograms, it is seen that all the DMTUFP-HMTA curing systems gave a single exotherm peak in the range of 92 to $160^{\circ} \mathrm{C}$. The kick-off temperature $\left(T_{i}\right)$, peak exothermic temperature $\left(T_{p}\right)$ and temperature of completion $\left(T_{f}\right)$ were obtained from the thermograms. The activation energy $\left(E_{a}\right)$ values for such a system (Table 3 ) do not vary widely, which indicates DMTUFP is more reactive towards the HMTA. The kinetic parameter $E_{a}$ (activation energy) was calculated by assuming that the curing reaction obeys Arrhenius-type kinetics and the peak maximum represents a point of constant conversion at a heating rate of $10^{\circ} \mathrm{C}$.

To obtain information about the properties of unreinforced crosslinked materials, cured samples were prepared using the same proportions and temperatures as presented in table 3 and Table 4 . The unreinforced cured DMTUFP-HMTA samples were prepared at $135 \pm 5^{\circ} \mathrm{C}$ for 8 hours, are dark brown in colour and are brittle materials that form powder under normal hand pressure. They are insoluble in all common organic solvents. IR spectra of all three cured products resemble in most aspects those of DMTUFP resin, how ever the spectra comprise more intense bands due to the $-\mathrm{CH}_{2}$ group and a weak band arround $1940 \mathrm{~cm}^{-1}$ due to the 1,2,3,5- tetra substituted benzene ring system ${ }^{26,27}$ The TG data are shown in Table 4.

Table 1 Elemental analysis of Dimethylol thiourea-formaldehyde-phenol resin

\begin{tabular}{|c|c|c|c|c|c|c|}
\hline \multirow{3}{*}{$\begin{array}{l}\text { Sr. } \\
\text { No. }\end{array}$} & \multirow{3}{*}{ Sample Code } & \multirow{3}{*}{ Nature of Resin } & \multicolumn{4}{|c|}{ Elemental Analysis } \\
\hline & & & \multicolumn{2}{|c|}{ Calculated } & \multicolumn{2}{|c|}{ Found } \\
\hline & & & $\% \mathrm{C}$ & $\% \mathrm{H}$ & $\% \mathrm{C}$ & $\% \mathrm{H}$ \\
\hline 1. & DMTUF & $\begin{array}{c}\text { Colourless } \\
\text { Viscous liquid }\end{array}$ & 26.47 & 6.77 & 24.89 & 6.33 \\
\hline 2. & DMTUFP1 & Yellow semi-solid & 65.06 & 6.02 & 64.78 & 5.69 \\
\hline 3. & DMTUFP2 & Yellow thick liquid & 73.56 & 5.21 & 73.23 & 5.10 \\
\hline 4. & DMTUFP3 & Yellow thick liquid & 74.00 & 5.337 & 73.77 & 5.23 \\
\hline
\end{tabular}

It shows that they all degrade in a single step, and their decomposition starts around $292{ }^{\circ} \mathrm{C}$. The degradation becomes faster between 550 and $650^{\circ} \mathrm{C}$. The weight loss was about $85-92 \%$ at $750^{\circ} \mathrm{C}$ in all cases. The degradation of all three systems in the range of 500 to $750^{\circ} \mathrm{C}$ indicates that the weight loss decreases with increase in the molar ratio of DMTUFP systems. This may due to in situ reaction of fragments degraded at an earlier stage.

Glass reinforced composites based on DMTUFP - HMTA systems have also been prepared at $135 \pm$ $5^{\circ} \mathrm{C}$, and are in the form of reddish brown sheets. The specific gravity of all composites is in the range 1.22 to 1.31 (table 5). Chemical resistance tests reveal that all composites have remarkable resistance to organic solvents and concentrated acid $(25 \% \mathrm{~V} / \mathrm{V})$. However, the concentrated alkali (25\% W/V) causes changes in their thickness and weight of about 1.0 to $1.4 \%$.The composites are found to have 
good mechanical properties(table5). The electrical resistivity of all the composites has been found to be in the range of $2.86 \times 10^{7}$ to $5.72 \times 10^{7} \mathrm{Ohms} \mathrm{cm}^{-2}$.

Table 2 Physical parameters of Dimethylol thiourea-formaldehyde and Dimethylol thiourea- formal dehyde-phenol resin

\begin{tabular}{|c|c|c|c|c|}
\hline $\begin{array}{c}\text { Sr. No. of } \\
\text { Resin }\end{array}$ & 1 & 2 & 3 & 4 \\
\hline $\begin{array}{c}\text { Sample code of } \\
\text { resin }\end{array}$ & DMTUF & DMTUFP1 & DMTUFP2 & DMTUFP3 \\
\hline $\begin{array}{c}\text { Efflux Viscosity } \\
\text { (s) }\end{array}$ & \multicolumn{4}{|c|}{ Time measured by flow cup 'B'5 (BS 1733) } \\
\cline { 2 - 5 } Dp & -25 & 45 & 34 & 17 \\
\hline $\bar{M}_{\mathrm{n}}$ & ---- & 14 & 12 & 8 \\
\hline \multirow{2}{*}{$\begin{array}{c}\text { Solubility } \\
\text { Number of OH } \\
\text { groups }\end{array}$} & All sample code resins w ere insoluble in water. Miscible in solvents like \\
alcohols, acetone,pyridine etc.
\end{tabular}

Table 3 curing characteristics of the DMTUFP-HMTA systems at $10 \mathrm{~K} \mathrm{~min}^{-1}$

\begin{tabular}{|c|c|c|c|c|c|}
\hline $\begin{array}{c}\text { Sr. } \\
\text { No. }\end{array}$ & $\begin{array}{c}\text { Sample } \\
\text { Code }\end{array}$ & $\begin{array}{c}\text { Kick-off } \\
\text { Temp., } \\
\mathrm{T}_{\mathrm{i}}\left({ }^{\circ} \mathrm{C}\right)\end{array}$ & $\begin{array}{c}\text { Peak } \\
\text { Temp., } \\
\mathrm{T}_{\mathrm{p}}\left({ }^{\circ} \mathrm{C}\right)\end{array}$ & $\begin{array}{c}\text { Final } \\
\text { Temp., } \\
\mathrm{T}_{\mathrm{f}}\left({ }^{\circ} \mathrm{C}\right)\end{array}$ & $\begin{array}{c}\text { Activation } \\
\text { Energy }\left(\mathrm{E}_{\mathrm{a}}\right) \\
\left(\mathrm{KJ} \mathrm{mol}^{-1}\right)\end{array}$ \\
\hline 1 & DMTUFP1 & 95 & 135 & 160 & 180.4 \\
2 & DMTUFP2 & 94 & 133 & 158 & 178.2 \\
3 & DMTUFP3 & 92 & 131 & 155 & 175.6 \\
\hline
\end{tabular}

Table 4. TGA of unreinforced DMTUFP : HMTA cured materials.

\begin{tabular}{|c|c|c|c|c|c|c|c|}
\hline \multirow{2}{*}{$\begin{array}{c}\text { Sr. } \\
\text { No. }\end{array}$} & \multirow{2}{*}{$\begin{array}{c}\text { Sample } \\
\text { Code }\end{array}$} & \multicolumn{6}{|c|}{ Percent weight loss at given temp. from TGA } \\
\cline { 3 - 8 } & $200^{\circ} \mathrm{C}$ & $300^{\circ} \mathrm{C}$ & $400^{\circ} \mathrm{C}$ & $500^{\circ} \mathrm{C}$ & $600^{\circ} \mathrm{C}$ & $750^{\circ} \mathrm{C}$ \\
\hline 1 & DMTUFP1 & 6.43 & 12.23 & 21.19 & 28.40 & 45.28 & 91.54 \\
\hline 2 & DMTUFP2 & 7.33 & 13.12 & 20.66 & 33.55 & 46.89 & 90.67 \\
\hline 3 & DMTUFP3 & 8.21 & 14.09 & 20.34 & 32.87 & 44.87 & 86.22 \\
\hline
\end{tabular}


Table 5. Mechanical and chemical properties of glass-reinforced DMTUFP-HMTA composites

\begin{tabular}{|c|c|c|c|c|c|c|c|c|}
\hline \multirow[t]{2}{*}{$\begin{array}{l}\text { Sr. } \\
\text { No. }\end{array}$} & \multirow[t]{2}{*}{$\begin{array}{l}\text { Sample } \\
\text { Code }\end{array}$} & \multicolumn{2}{|c|}{$\begin{array}{l}\text { \% change on } \\
\text { exposure to } 25 \% \\
\text { (W/V) NaOH }\end{array}$} & \multirow[t]{2}{*}{$\begin{array}{l}\text { Specific } \\
\text { Gravity }\end{array}$} & \multirow{2}{*}{$\begin{array}{l}\text { Flexural } \\
\text { strength } \\
\mathrm{Kg} / \mathrm{cm}^{2}\end{array}$} & \multirow{2}{*}{$\begin{array}{c}\text { Impact } \\
\text { strength } \\
\mathrm{Kg} / \mathrm{cm}^{2}\end{array}$} & \multirow[t]{2}{*}{$\begin{array}{l}\text { Rockwell } \\
\text { hardness }\end{array}$} & \multirow{2}{*}{$\begin{array}{l}\text { Resistivity } \\
\left(\mathrm{Ohms} / \mathrm{cm}^{2}\right)\end{array}$} \\
\hline & & Thickness & Weight & & & & & \\
\hline 1 & DMTUFP1 & 1.0 & 1.3 & 1.22 & 243 & 12.75 & 125 & 18.22 \\
\hline 2 & DMTUFP2 & 1.2 & 1.35 & 1.26 & 249 & 13.66 & 131 & 19.16 \\
\hline 3 & DMTUFP3 & 1.4 & 1.4 & 1.31 & 255 & 13.77 & 133 & 20.2 \\
\hline
\end{tabular}

${ }^{a}$ Reinforcement, E glass cloth, plain weave, $25 \mathrm{~mm}, 10$ ply, Resin content: $40 \pm 2$ wt $\%$. Molar ratio DMTUFFP : HMTA $=1: 1(\mathrm{~mol} / \mathrm{mol})$. Curing temperature $135 \pm 5^{\circ} \mathrm{C}$, time $8 \mathrm{~h}$. Pressure 60-70 psi. Composite size $250 \mathrm{~mm} \times 250 \mathrm{~mm} \times 3.0-3.5 \mathrm{~mm}$.

${ }^{\mathrm{b}}$ Chemical resistance to alkali $(25 \% \mathrm{~W} / \mathrm{V} \mathrm{NaOH})$ : composites are unaffected by organic solvents and concentrated acid ( $25 \% \mathrm{~V} / \mathrm{V} \mathrm{HQ})$.

It was also observed that the produced composites have better alkali resistivity than those of commercial novolac/resol-based composites.

\section{Acknowledgments}

We are grateful to Dr. D. J. Desai Principal, V.P \& R.P.T.P Science college, for providing the necessary research facilities. We are also grateful to Dr. H. K. Patel, Joint secretary, Charutar Vidya Mandal, Vallabh Vidyanagar, for their constant encouragement.

\section{References}

1 Schuermann Hans U. S., Nov. 3; Vol. 37, 2, 300, 976.

$2 \quad$ Nalwa Harisingh Vasudevan and Padma, Mater Res. Bull., 1983, Vol. 99, 18(7), 897 (Eng).

3 Ripper Kurt, U S, Apr. 14; Vol. 36, 2, 279, 493.

4 Schmidt John H and Daniels Rupert S, the Bakelite Corp, Can., Aug 4, 1931; Vol. 25, 313, 958.

5 Farbenind I G, Fisemann Karl A and Kuchenbuch Johanras G, Ger, Dec 13, 1929; Vol. 25, 516, 995.

$6 \quad$ Kraus Wilhelm, American cynamide Co. U S, Oct.8, 1932; Vol. 29, 2, $016,285$.

$7 \quad$ Kraus Wilhelm, Brit, July 25, 1935; Vol. 30, 432, 637.

8 Igarashi Yuriko and Takahashi and Masaaki, Kureha Chemical Industry Co. Ltd., Ger, Offen. DE 19 Jul 1984; Vol. 101, 3, 401, 056.

9 Di Domenico and Edward Jr. (Henkel Corp.) U.S., 29 May 1984; Vol. 101, US 4, 451, 622.

10 Asahi Chemical Industry Co. Ltd., Jpn., Kokai Tokkyo Koho Jp; 17 Oct.1984; Vol. 102, 59, 182, 284 $[84,182,284]$.

11 Fuji Photo Film Co. Ltd., Jpn, Kokai Tokkyo Koho Jp; 02 Jul 1984; Vol. 102, 59, 114, 537.

12 Matsutani Koichi, Inana Shingekatsu and Okamato Hideo, Unitikia Co., Ltd., Japan, 19 Sep. 1972; Vol. 78, Jp 72 37, 239.

13 Jones F W, Leeder J D and Wemyss A M, Div. Text. Ind., SIRO, Geelong, Aust., J. Text. Inst. 1972,I. 77, 63(3), 135 (Eng).

14 Hoskinson R M. and Russel I M, Div. Test. Ind. SIRO, Geelong, Aust., J. Text. Inst. 1973 , 79, 64(3), 146 (Eng). 
Kozlova G I, Dubikovskaya L V, Sereda N I. and Litinoe Proizvod, USSR 1973, 80(6), 4.5 (Russ).

16 Kimura Hiroo, Arimoto Heiji, Uejima Hiromoto and Taniguchi Tadashi, Unitika Co., Ltd., Japan, 30 Jan 1973, 80, 73 03, 360.

17 Kimura Isao, Yata, Sizukuni and Nippon Kynol, Inc., Japan, Ger. Offen., 24 Jan 1974, 81, 2, 331, 213.

18 Frenkel Erich, Walter and Brit., 4 Oct., 1939, 35, 513,113.

19 Tideman I G T and Sanclemente M R, Poly. Res. Dep., Seattle, Wash. J. Appl. Polym. Sci.1973, 79, 17(6), 1813-18(Eng).

20 Seeholzer Joset, Michaud Horst, Mangs Josefa and Poschinger Wilhelm, Ger Offen., Dec. 1972, $82,2,260,186$.

Saito and Minoru, Unitika Ltd., Japan Kokai , Vol. 88, pp 77, 134, 887

Chaterjee S K and Gupta N D, J. Polym. Sci. Chem., 1973, 31, 11, 1261.

MitraR P and Chatterjee S K, J. Sci. Ind. Res. (India), 1961, 32, 20 B, 310.

Bance S, Handbook of Practical Organic Microanalysis New York, Wiley, 1980.

Patel H S and Patel H D, High Perform. Polym., 1992, 4, 35.

Parikh V, M., Absorption spectroscopy of Organic molecule by Addison-Wesley Publishing company , Phillipines, 1974, 248-252.

27 Young C W , Du Vall R B and Wright N, Anal. Chem. 1951, 23, 709. 


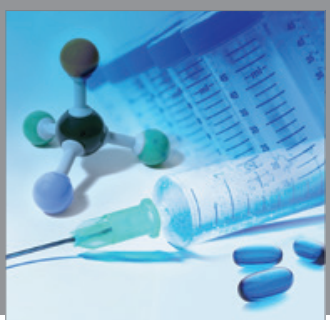

International Journal of

Medicinal Chemistry

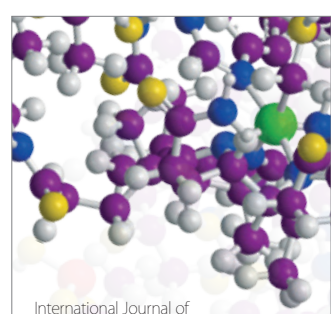

Carbohydrate Chemistry

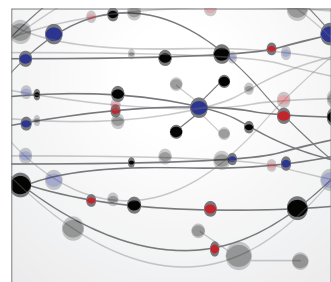

The Scientific World Journal
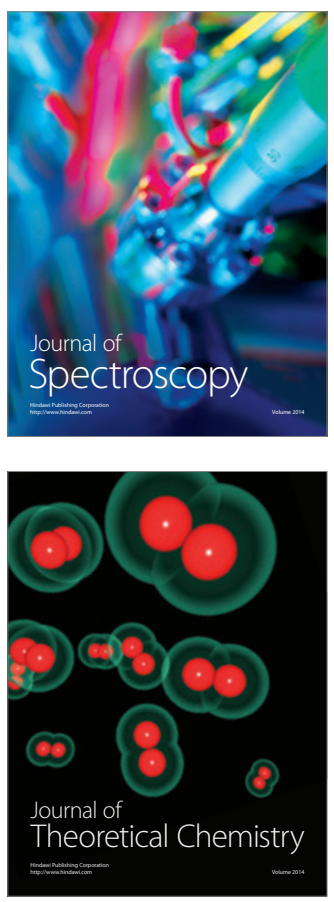
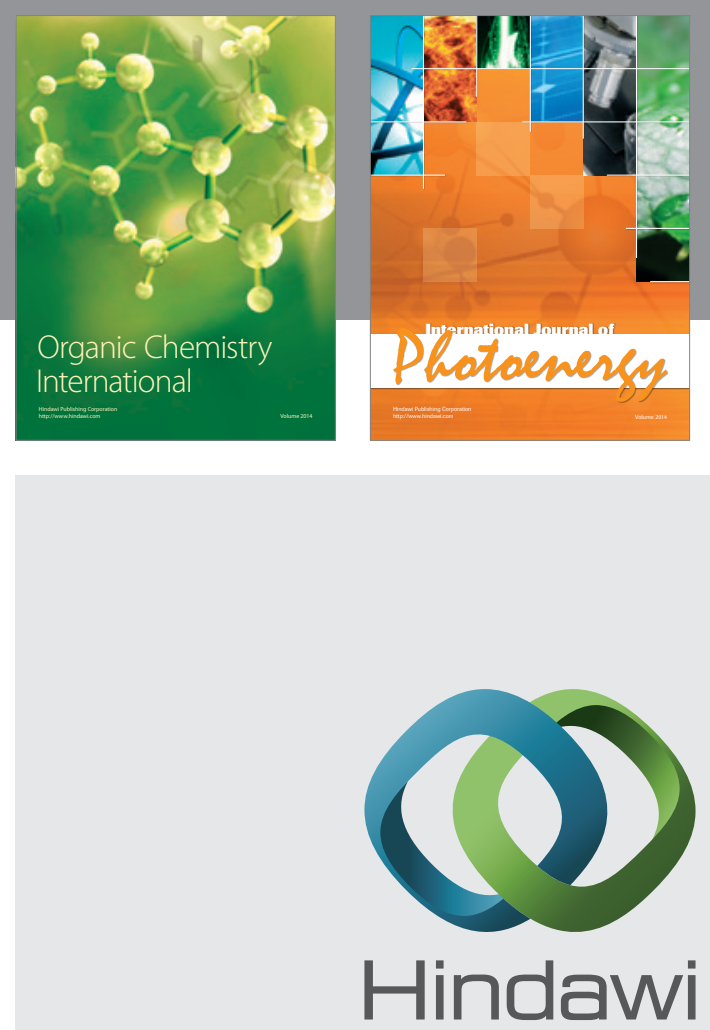

Submit your manuscripts at

http://www.hindawi.com
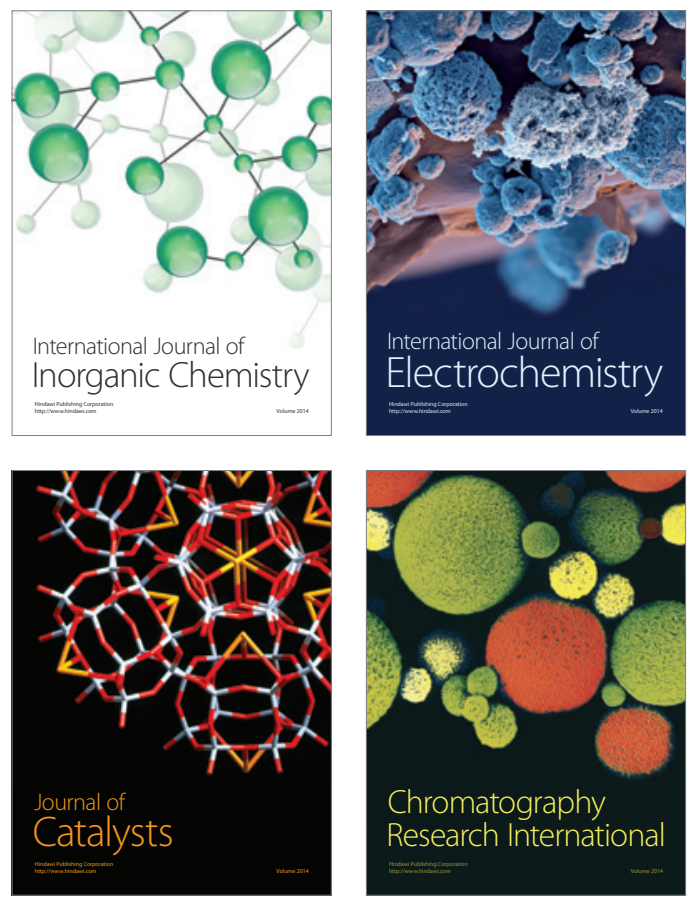
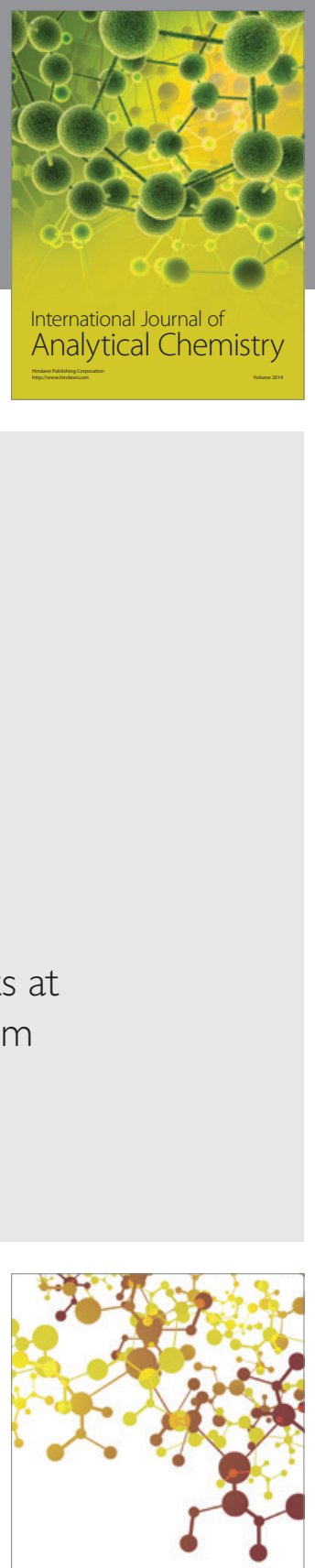

Journal of

Applied Chemistry
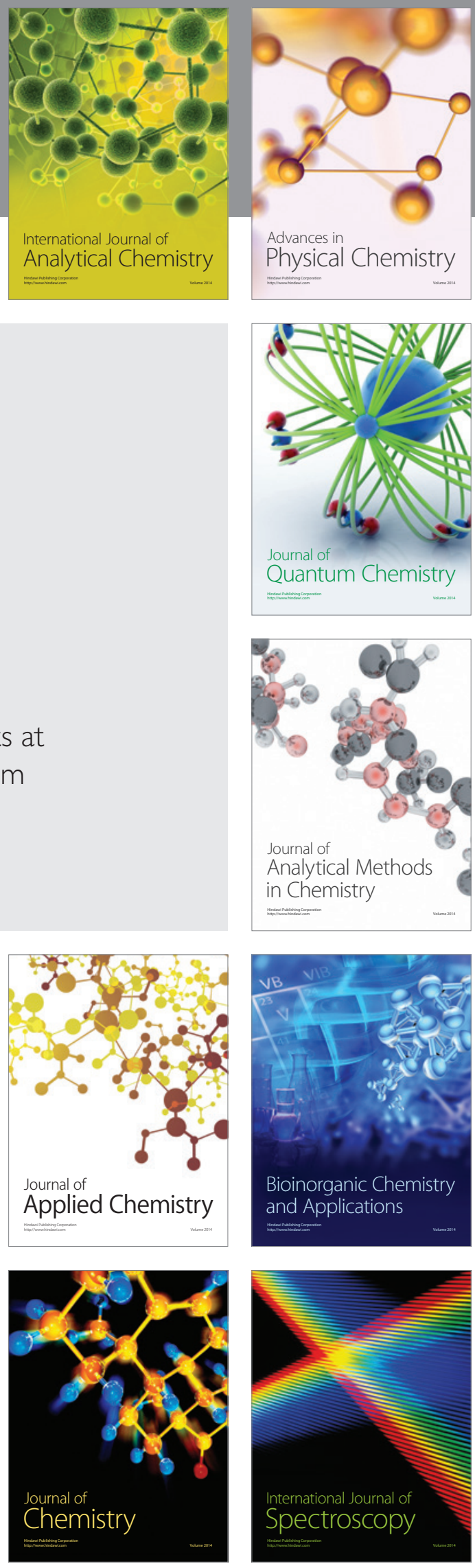